\title{
Dinamika Kehidupan Sosial Ekonomi Nelayan di Desa Kedonganan Kabupaten Badung 1990-2018
}

\author{
Puput karlina*, Ida Ayu Wirasmini Sidemen \\ Prodi Sejarah, Fakultas Ilmu Budaya, Unud \\ [pkarlina26@gmail.com] \\ Padang Pariaman, Sumatera Barat, Indonesia \\ *Corresponding Author
}

\begin{abstract}
The title of this research is the Dynamics of Social Economy of Fishermen in Kedonganan Village 1990-2018. The formulation of the problems of this study are 1) How is the Life of the Kedonganan People?, 2) What is the role of the Adat Village and the Regional Government? ,3) What is the dynamics of the socioeconomic life of the fishing community in Kedonganan? In this study using the methodology of social history and the theory used is the theory of history and the theory of social change where these two theories can be applied to explain in this research the Historical Explanation theory, namely explaining events in the past, and social change theory that can be seen from the results of research namely changes that occur in the fishing community Kedonganan. In this study found the results of fishermen in Kedonganan are not sea fishermen but "land" fishermen.
\end{abstract}

\section{Keyword : Dynamics, Socio-Economic and Fishermen}

\begin{abstract}
Abstrak
Judul dari peneltian ini adalah Dinamika Kehidupan Sosial Ekonomi Nelayan di Desa Kedonganan 1990-2018. Adapun rumusan permasalahan dari penelitian ini adalah diantaranya 1) Bagaimana Kehidupan Masyarakat Kedonganan ?, 2) Apa peran dari Desa Adat dan Pemerintah Daerah? , 3) Bagaimana Dinamika kehidupan sosial-ekonomi masyarakat nelayan Kedonganan? Dalam penelitian ini menggunanakan metodologi sejarah sosial dan Teori yang digunakan adalah teori sejarah dan teori perubahan sosial dimana kedua teori ini bisa diaplikasikan untuk menjelaskan dalam penelitian ini yaitu teori Historical eksplanation yakni menjelaskan kejadian di masa lampau, serta teori perubahan sosial yang bisa dilihat dari hasil penelititian yaitu perubahan yang terjadi pada masyarakat nelayan Kedonganan. Dalam penelitian ini menemukan hasil tentang nelayan yang ada di Kedonganan saat ini merupkan bukan nelayan laut melainkan nelayan "darat".
\end{abstract}

Kata Kuci : Dinamika, Sosial-Ekonomi dan Nelayan

\section{PENDAHULUAN}

Indonesia merupakan negara kepulauan karena terdiri dari banyak pulau yang mencakup laut, danau dan selat. Oleh karena itu, Indonesia juga disebut sebagai negara maritim. Bahkan ada sebuah anekdot yang menyebutkan bahwa nenek moyang Indonesia adalah seorang pelaut. Hal tersebut kemudian menjadi wajar mengingat dua pertiga wilayah Indonesia didominasi oleh perairan atau laut, sehingga 
mengakibatkan masyarakat Indonesia yang tinggal di sepanjang pantai bermata pencaharian sebagai nelayan. (Iriani,dkk, 2001)

Oleh karena itu, masyarakat yang berada di pesisir sangat memanfaatkan perairan laut sebagai sumber kehidupan untuk memenuhi kebutuhan hidup. Faktor utama yang mendorong bekerja sebagai nelayan adalah untuk mempertahankan hidup keluarga dan kelompok nelayan sehingga bisa memenuhi kebutuhan hidup. Dalam penelitian ini yang menjadi objek penelitian adalah masyarakat nelayan yang ada di kelurahan Kedonganan, Kecamatan Kuta, Kabupaten Badung, Provinsi Bali. Kabupaten Badung merupakan salah satu Kabupaten di provinsi Bali yang terdiri dari daratan dan lautan. Salah satu masyarakat Kabupaten Badung yang bermata pencaharian sebagai nelayan berada di Kelurahan Kedonganan.

Kedonganan merupakan desa pesisir di mana bagian sisi barat dan timur desa ini adalah laut. Hal tersebut menyebabkan sebagian besar penduduk Kelurahan Kedonganan pada mulanya bergerak di sektor perikanan dan kelautan. Sampai tahun 1990 sudah terdapat sekitar 90 persen dari warga Kelurahan Kedonganan yang berprofesi sebagai nelayan dan sebagian lagi berprofesi sebagi pedagang ataupun buruh. (Kusnadi, 2007)

Penduduk Kedonganan yang berada di wilayah pesisir pantai umumnya bermata pencaharian sebagi nelayan. Laut merupakan sumber daya alam yang sangat membantu dalam kehidupan masyarakat Kedonganan. Kelurahan Kedonganan memberi corak nelayan karena ekotipe yang diapit oleh pantai dan laut, yakni di bagian barat dan bagian timur desa. Perubahan-perubahan yang terjadi di Kedonganan adalah perubahan dibidang perikanan dan kelautan yang melibatkan para nelayan.(Arif Satria, 2001)

Berdasarkan latar belakang tersebut di atas, penelitian ini berjudul "Dinamika Kehidupan Sosial Ekonomi Nelayan di Desa Kedonganan Kabupaten Badung Tahun 1990-2018.

Adapun tujuan dari Artikel ini, sebagai berikut. 1) Untuk mengetahui kehidupan masayarakat nelayan, 2) Untuk mengetahui sejauh mana peran Desa Adat dan Pemerintah Daerah dan 3) Untuk mengetahui dinamika atau pergerakan yang terjadi di masyarakat nelayan.

\section{METODE}

Metodologi atau science of methods merupakan ilmu yan membincangkan atau membicarakan jalan atau alat untuk melakukan pendekatan yang diterapkan dalam penelitian. (Kuntowijoyo,2001). Metodologi yang digunakan ini akan dijadikan sebagai alat pengamat, sehingga studi kasus dalam penelitian ini dapat terungkap secara kritis dan objektif dan bisa mengungkapan aspek-aspek secara kronologis. Pendekatan yang digunakan dalam penulisan ini adalah pendekan sejarah sosial. Pendekatan sejarah sosial dapat dipahami sebagai setiap gejala sejarah yang berdampak pada kehidupan sejarah sosial suatu komunitas atau kelompok. Sejarah sosial membahas kehidupan karena dalam kehidupan pasti ada interaksi sosial. Interaksi terjadi karena manusia adalah makluk sosial yang tidak bisa hidup sendiri.

Selain metodologi Sejarah Sosial, sebagai pelengkap penelitian ini juga akan menggunakan Sejarah Lisan. Kuntowijoyo menyebutkan bahwa Sejarah Lisan mempunyai sumbangan yang besar dalam mengembangkan substansi penulisan sejarah, di antaranya: Pertama, dengan sifatnya yang kontemporer Sejarah Lisan memberikan kemungkinan yang hampir-hampir tidak 
terbatas untuk menggali sejarah dan pelaku-pelakunya. Kedua, Sejarah Lisan dapat mencapai pelaku-pelaku sejarah yang tidak disebutkan dalam dokumen. Dengan kata lain, dapat mengubah citra sejarah yang eletis kepada citra sejarah yang egalitarian. Ketiga, Sejarah Lisan memungkinkan perluasan permasalahan sejarah karena sejarah tidak lagi dibatasi kepada adanya dokumen tertulis.

Sumber-sumber yang dapat dipakai oleh sejarawan dalam sejarah lisan adalah kenangan, desas-desus atau keterangan saksi mengenai kejadian dan situasi yang ada pada kondisi masa kini, yaitu hal-hal yang terjadi selama masa hidup seorang informan.

\section{HASIL DAN PEMBAHASAN}

\section{Kehidupan Masyarakat Pesisir Kedonganan}

Di Kedonganan tidak hanya masyarakat asli Kedonganan saja yang ada untuk saat ini, melainka adanya masyarakat pendatang dari luar Pulau Bali, yaitu dari Jawa, Madura, Sulawesi dan daerah lainnya. Masyakat pendatang yang ada di Kedonganan merupakan masyarakat yang mencari nafkah di Kedonganan, ada yang bekerja sebagai buruh nelayan dan juga bekerja sebagai penjual ikan. Hubungan antara masyarakat pendatang dengan masyarakat asli Kedonganan terjalin cukup harmonis. Ini bisa dilihat pada saat acara keagamaan yang ada di Desa Kedonganan dimana masyarakat pendatang juga terlibat didalamnya. (Martha Wasak, 2017)

Kedonganan terkenal dengan sebutan kampung nelayan karena wilayahnya yang berada di wilayah pantai. Oleh karena itu banyak pula berbagai aktivitas masyarakat Kedonganan yang berhubungan dengan pantai. Setiap hari di wilayah pantai Kedonganan dapat dilihat selalu adanya jukung-jukung yang bersandar dipinggir pantai. Pekerjaan sebagai nelayan merupakan mata pencaharian utama bagi masyarakat pesisir di Kedonganan. Sebagaimana mata pencaharian masyarakat pesisir lainnya yang umumnya bekerja sebagai nelayan atau melaut.

Oleh karena hanya dengan melaut bagi sebagian besar masyarakat pesisir bisa memenuhi kebutuhan hidup seharihari. Sementara bagi masyarakat nelayan Kedonganan, menurut salah seorang informan bernama I Nyoman Astra menyebutkan bahwa masyarakat Kelurahan Kedonganan lebih memilih pekerjaan sebagai seorang nelayan, karena dapat menghasilkan uang setiap harinya dan dapat digunakan untuk memenuhi kebutuhan keseharian. (Joni Trio Wibowo, dkk, 2016)

Sebelum tahun 1990-an, I Nyoman Astra sudah merupakan seorang nelayan di Kedonganan. I Nyoman Astra mengaku bahwa sejak duduk di bangku Sekolah Dasar sudah ikut membantu sang ayah yang merupakan seorang nelayan dalam menangkap ikan dan melaut.Salah satu contoh masyarakat nelayan pendatang di Kedonganan adalah bernama Ayyik, yang berasal dari Kabupaten Banyuwangi Jawa Timur. Ia bekerja sebagai nelayan di Kedonganan sejak tahun 2000-an. Namun pada awalnya ia bekerja sebagai buruh nelayan.

Akan tetapi dengan berkembangnya zaman Ayyik berhasil membeli sebuah jukung sendiri, sehingga jukung yang Ayyik gunakaan saat ini adalah milik sendiri. Selama menangkap ikan, Ayyik melaut sendiri dengan peralatan pancing dan jaring.

Di Kedonganan sendiri perlatan alat tangkap ikan pernah mengalami alat tangkap yang modern, yang mana alat tangkap ini sudah dikenalkan oleh Dinas Perikanan dan Kelautan Republik Indonesia, selain untuk memperkenalkan alat tangkap modern, peralatan ini juga dianggap bisa meningkatkan taraf hidup 
masyarakat nelayan dengan hasil tangkapan yang maksimal dan lebih banyak. Alat-alat penangkapan ikan yang modern seperti ini sudah diperkenalkan sejak tahun 1961 oleh sebuah perseroan dan perusahaan perikanan laut yan bernama PT Dhana Matsya. (I Wayan Tagel Eddy \& Anak Agung Ayu Rai Wahyuni, 2019).

Modernisasi perikan yang terjadi di Kedonganan merupakan suatu proses perubahan yang terjadi mempengaruhi kehidupan sosial-ekonomi. Sayangnya modernisasi penangkapan ikan ini tidak tidak bertahan lama, ketika kapal purse saine di pindahkan pendaratannya ke daerah Pengambengan. Adapun alasan Pemerintah memutuskan memindahkan kapal tersebut karena Kabupaten Badung merupakan daerah yang direncakan akan dijadikan daerah tujuan pariwisata khususnya Kedonganan yang letaknya dekat dengan daerah tujuan wisata yaitu Kuta, sehingga pendaratan ikan dianggap mengganggu pemandangan para wisatawan.

Dewasa ini , usaha penangkapan ikan yang dilakukan oleh para nelayan Kedonganan bisa dikatakan menggunakan teknologi tradisional kembali, seperti jukung, jaring, dayung dan motor tempel. Oleh karena hal tersebut nelayan yang ada di Kedonganan masih menggunakan alat transportasi melaut yang masih tradisional untuk menjaga kelestarian biota laut.

Berkaitan dengan musim para nelayan Kedonganan untuk membedakan adanya arus laut searah dan arus laut yang berlawanan arah (bolak-balik) dalam melaut menggunakan arah tiupan angin. Menurut Efendi selama musim penghujan sekitar bulan November hingga April, di perairan selat Bali arus laut bergerak searah ke Utara. Sebaliknya, selama musim kemarau di perairan ini bergerak arus bolak-balik, yaitu Utara ke Selatan. (Endang Retnowati, 2011)
Pemasaran hasil ikan tangkapan yang dilakukan oleh nelayan Kedonganan, yaitu dengan cara menjualnya melalui agen perantara yang ada di Kedonganan. Melalui agen perantara hasil ikan tangkapan para nelayan nelayan tersebut di pasarkan oleh para agen perantara ke pedangang-pedagang dan pembeli ikan.

Pada musim ikan seperti yang disebutkan di atas biasanya suasana di pantai Kedonganan sangat ramai oleh aktivitas kenelayanan. Pada saat musim ikan, maka banyak berdatangan nelayannelayan yang berasal dari luar Kedonganan yang disebut sebagai nelayan andon, seperti dari Banyuwangi. (Lucky Zamzami, 2016).

\section{Sinergi Nelayan dengan Desa Adat dan Pemerintah Daerah}

a. Peran Desa Adat

Dalam keseharian masyarakat nelayan Kedonganan, Desa Adat juga mempunyai peran yang sangat berpengaruh terhadap kehidupan masyarakat nelayan Kedonganan. Peranan Desa Adat dalam hal ini sebagaimana sudah disinggung sebelumnya bahwa ada semacam awigawig atau semacam undang-undang atau peraturan yang harus dipatuhi dan diikuti oleh masyarakat nelayan di Kedonganan, bahwa tujuan dari dibuatnya awig-awig ini adalah untuk memberikan pedoman dalam berperilaku bagi para masyarakat nelayan dalam hidup bermasyarakat, terutama dalam melakukan kegiatan penangkapan ikan serta untuk menjaga keutuhan masyarakat nelayan Kedonganan itu sendiri. Selain itu saat ini nelayan Kedonganan mendapatkan bantuan pinjaman melalui Lembaga Perkreditas Desa. (Dety Sukmawati, 2008)

Di Kelurahan Kedongan sendiri terdapat sebuah Lembaga Perkreditasn Desa (LPD) yang dikelola oleh Desa Adat. Namun demikian, pada tahun 1995 
wilayah Kedonganan sudah mulai terjamah oleh perkembangan kepariwisataan. Keberadaan pantai Kedonganan sebagai pusat perikanan di Badung dipandang oleh masyarakat sebagai sebuah peluang untuk berkembang. Peluang yang dilihat pun cukup menjanjikan, yakni wisata kuliner. Dari sinilah kemudian berdiri kafe-kafe yang secara khusus menyediakan menu hidangan ikan laut dengan segala variasinya di sepanjang pantai Kedonganan. Peranan LPD Desa Adat di Kelurahan Kedonganan berikutnya adalah mengembangkan progam penataan pantai Kedonganan. Progam yang kemudian menjadi progam desa ini mulai dilaksanakan pada tahun 2007. Semenjak tahun 2007 Desa Adat Kedonganan yang didukung oleh Pemerintahan Kabupaten Badung (Purwadi Soeradiredja, 2019)

Sebenarnya, tidak hanya kafe-kafe saja di mana LPD memberikan dukungan, tetapi LPD juga memberikan dukungan kepada masyarakat nelayan, yaitu dengan peinjaman kredit kepada masyarakat nelayan. Salah satu contoh nelayan yang mendapat bantuan pinjaman pengkreditan dari LPD Desa Adat Kedonganan, yaitu I Nyoman Suwerta. Nyoman Suwertha merupakan satu di antara segelintir masyarakat nelayan Kedonganan yang mendapatkan pijaman dari LPD yang bertujuan untuk membeli peralatan nelayan seperti jaring.

\section{b. Peran Pemerintah Daerah}

Selain itu, peranan pemerintah juga bisa dilihat dari adanya kegiatan penyuluhan kepada nelayan-nelayan kecil dan pembudidaya ikan kecil yang dilakukan oleh pemerintah. (I Gede Made Subagiana, dkk, 2018)

Selanjutnya pemerintah juga mengeluarkan Peraturan Daerah Provinsi Bali Nomor 11 tahun 2017 tentang Bendega. Di Provinsi Bali, keberadaan Bendega masih ada dalam perwilayahan yang menyebar di beberapa Kabupaten/Kota. Bendega merupakan lembaga tradisional yang bersifat sosial budaya dan relegius. Bendega bergerak dibidang perekonomian, sosial dan kebudayaan. Sementara dalam bidang perikanan Bendega merupakan bagian dari budaya tradisional Bali. Bendega yang merupakan bagian dari budaya tradisional Bali berperan dan berfungsi untuk meningkatkan kesejahteraan Krama Bendega dan bersumber pada falsafah Tri Hita Karana dan pada ajaran agama Hindu di Bali.

Sementara itu, di Kedonganan sendiri jumlah nelayan yang ada sekarang ini menurut dari data profil Kelurahan Kedonganan kurang lebih sekitar ada 257 orang. Jumlah dari nelayan Kedonganan tersebut tergabung dalam empat kelompok masyarakat nelayan Kedonganan. Keempat kelompok nelayan tersebut, di antaranya: 1) Kelompok Nelayan Putra Bali (KNPB), 2) Kelompok Nelayan Kertha Bali (KNKB), 3) Kelompok Nelayan Ulam Sari (KNUS), dan 4) Kelompok Nelayan Segara Ayu (KNSA).

Dari ke empat kelompok nelayan tersebut hanya dua di antaranya yang telah mempunyai payung hukum, yaitu Kelompok Nelayan Putra Bali dan Kelompok Nelayan Kertha Bali. Setelah dikukuhkannya Kelompok Nelayan Putra Bali pada tahun 2012 dan demi kelancaran administrasi bagi Kelompok Nelayan Putra Bali di Kabupaten Badung, akhirnya Kelompok Nelayan Putra Bali mempunya SK yang sah dari Kepala Dinas Perikanan Kabupaten Badung yang mana SK tersebut dikeluarkan menimbang dari surat permohonan Kelompok Nelayan Putra Bali Nomor 02/KNPB/XI/2016, tanggal 10 November 2016 tentang permohonan pengesahan. Hasil dari pertimbangan sebagaimana yang dimaksud perlu menetapkan keputusan Bupati tentang 
pembentukan Kelompok Nelayan Putra Bali pada tahun 2017.

Tempat Pelelangan Ikan (TPI) yang terdapat di Kedonganan merupakan salah satu tempat bagi nelayan Kedonganan untuk menjual hasil ikan tangkapannya. TPI tersebut pada dasarnya merupakan salah satu bantuan yang diberikan oleh pemerintah dengan tujuan agar nelayan Kedonganan terhindar dari sistem ijon pada waktu itu. TPI yang terdapat di Kelurahan Kedonganan tersebut diresmikan pada tanggal 11 maret 1979, TPI tersebut mempunyai peranan penting dalam membantu pemasaran ikan nelayan Kedonganan. (I Gede Ary Candra Pramana, 2017)

Kabupaten Badung merupakan daerah yang mempunyai potensi perikanan yang cukup besar. Salah satu wilayah yang ada di pesisir Kabupaten Badung adalah Kedonganan yang mana masyarakatnya secara umum bekerja sebagai nelayan. Di Kedonganan sendiri terdapat sebuah pelabuhan tipe D yang menjadi Pangkalan Pendaratan Ikan (PPI). Pelabuhan ini merupakan salah satu pelabuhan yang melayani kapal perikanan yang melakukan kegiatan perikanan di perairan pedalaman dan perairan kepulauan.

\section{Dinamika Kehidupan Masyarakat Nelayan Kedonganan}

Dinamika merupakan sesuatu yang mengandung arti tenaga kekuatan, selalu bergerak, berkembang dan dapat menyesuaikan diri secara memadai terhadap keadaan.. Di daerah pesisir pantai terdapat pula suatu kumpulan manusia yang memiliki pola hidup dan tingkah laku serta karakteristik tertentu. Masyarakat yang tinggal di wilayah pesisir pantai umumnya memiliki pekerjaan sebagai nelayan agar bisa memenuhi kebutuhan ekonominya. (Sinta Rshayu,2017)

Kedonganan merupakan desa pesisir sehingga sebagian besar penduduknya bergerak disektor perikanan dan kelautan. Pekerjaan sebagai nelayan adalah pekerjaan yang pokok masyarakat Kedonganan hingga tahun 1990 an, masyarakatnya masih $90 \%$ sebagai nelayan. Dan pada tahun 1995 wilayah Kedonganan baru terjamah oleh pariwisata. Keberadaan pantai Kedonganan dilihat oleh warga sebagai peluang untuk berkembang, peluang yang sangat menjanjikan yaitu wisata kuliner. Akan tetapi semenjak tahun 2007 mulai lah pembangunan dan penataan kawasan pantai Kedonganan yaitu berdirinya kafekafe , yang merupakan cara mensejahterakan masyarakat Kedonganan. Dari tahun ini lah masyarakat Kedonganan mulai mengalami perubah-perubahan, yang mana akan dijelaskan dibawah ini lebih lanjut mengenai perubahan-perubahan apa saja yang ada di Kedonganan terutama perubahan yang ada pada nelayan-nelayan Kedonganan. Dimana dengan adanya pemanfaatan objek wisata dan pengelolan kafe-kafe yang ada di Kedongan serta bantuan dari LPD Desa Adat Kednganan bisa merubah kehidupan nelayan Kedonganan, salah satunya Nelayan yang ada di Kedongana untuk sekarang ini bukan nelayan yang melaut melainkan nelayan yang sudah mempunyai Anak Buah Kapal (ABK). (Lisebet Sihombing, Saptono Nugroho, 2018).

Perubahan kehidupan perekonomian yang lebih baik itu merupakan perubahan kehidupan dalam memenuhi perekonomian sehari-hari dari seorang keluarga nelayan yang konotasinya di sebut miskin namun mampu menjadi pemilik jasa bakar hasil laut, pengelola kafe bahkan menjadi seorang nelayan yang mempunyai ABK. Adanya perubahan kehidupan perekonomiannya yang dialami mampu menjadi motivasi dalam kehidupan masyarakat nelayan lainnya. . (Endri Yunita, dkk, 2018). 
Dengan adanya perubahan ekonomi, kehidupan sosial secara otomatis juga mengalami perubahan. Status adalah suatu kedudukan sosial dalam diri seseorang di lingkungan masyarakat yang dapat diperoleh dengan sendirinya yang bersifat otomatis melalui usaha ataupun karena pemberian. Oleh karena itu , setiap orang dalam suatu kehidupan bermasyarakat akan berusaha untuk mencapai status sosial yang lebih tinggi.

\section{SIMPULAN}

Nelayan yang ada di Kedongana dimana yang awalnya merupakan masyarakat miskin yang dalam artian belum bisa mengelola hasil laut yang mereka miliki untuk meningkatkan kesejahteraan hidup, dan bahkan hasil dari pariwisatapun belum bisa dirasakan. Namun akan tetapi pada tahun 2007 masyatakat Kedonganan bangkit lagi dari keterpurukan, pada tahun 2007 sepanjang pantai Kedonganan di Bantu oleh LPD dan Pemerintahana badung beserta Desa Adat membenah pantai dengan menata kafe-kafe tersebut menjadi 24 buah kafe Masyarakat Kedonganan dilibatkan dari awal pendirian

Nelayan yang ada di Kedongana merupakan nelayan yang sudah tidak melaut lagi melain kan sudah menjadi nelayan " darat ". Yang dimaksud dengan nelayan "darat" adalah dimana nelayan Kedonganan saat ini merupakan nelayan pemilik armada atau bisa disebut dengan pengambek dan yang menangkap ikan dilaut adalah nelayan buruh atau andon. Tidak hanya itu Kedonganan saat ini juga mempunyai sebuah kegiatan yang berhubungan antara laut dan nelayan yang mana diberi nama Minawisata Kedonganan yang mana acara ini akan diadakan setiap tahun agar dengan Minawisata ini terus membangun generasi muda dan untuk merubah perekonomian nelayan yang ada di Kedonganan. Minawisata ini sangat mendorong perekonomian masyatakat nelayan.

Oleh karena itu, sektor dibidang bahari merupakan "blue" ekonomi, yang merupakan suatu kekuatan ekonomi yang berada disisi bahari. Dan disisi lain pantai memiliki potensi dari sisi ekonomis, dimana pantai bisa dipergunakan untuk sumber ekonomi masyarakat. Dan apabila "blue" ekonomi disenerginakan dengan "orange" ekonomi.

\section{DAFTAR PUSTAKA}

Iriani, dkk. 2001. Kehidupan Sosial Ekonomi Masyarakat Nelayan di Desa Sago Kecamatan IV Jurai Kabupaten Pesisir Selatan. Padang: PD. INTISSAR.

Kuntowijoyo. 2003. Metodologi Sejarah Edisi Kedua Yogyakarta: Tiara Wacana.

Kusnadi. 2007. Strategi Hidup Masyarakat Nelayan. Yogyakarta: Lkis

Satria, Arif. 2001. Dinamika Modernisasi Perikanan: Formasi Sosial dan Mobilitas Nelayan. Bandung: Humaniora Press.

Endri Yunita, dkk, 2018. Kondisi Sosial Ekonomi Masyarakat Nelayan di Pantai Labuhan Jukung Krui Pasca Terbentuknya Kabupaten Pesisir Barat, Jurnal Studi Sosial, Vol. 6 No 1.

Gede, I Ary Candra Pramana, 2017. Pengaruh Faktor Ekonomi Sosial dan Demografi Terhadap Pendidikan Anak Nelayan di Kabupaten Badung, Jurnal Piramida, Vol. XIII No 1.

Gede, I Made Subagiana, dkk, 2018. Model Pemberdayaan Masyarakat 
Pesisir pada Tiga Perkampungan Nelayan Air Kuning, Pengambengan dan Candi Kusuma Kabupaten Jembrana Provinsi Bali, Jurnas Bisnis dan Kewirausahan, Vol. 14. No. 2.

Lucky Zamzami, 2016. Dinamika Pranata Sosial Terhadap Kearifan Lokal Masyarakat Nelayan Dalam Melestarikan Wisata Bahari, Jurnal Antropologi, Vol. 18 No 1.

Retnowati, Endang 2011. Nelayan Indonesia Dalam Pusaran Kemiskinan Struktural, Jurnal Perspektif, Vol. XVI. No. 3.

Sihombing, Lisbet dan Saptono Nugroho. 2018. Peran Kelompok Nelayan Dalam Aktivitas Pariwisata di Desa Kedonganan Kuta, Bali, Jurnal Destinasi Pariwisata, Vol. 5 No 2.

Soeriadiredja, Purwadi. 2019.Strategi Masyarakat Nelayan Kedonganan Menghadapi Kemiskinan, Jurnal Ilmu-ilmu Budaya, Vol XIX No 1.

Sukmawati, Dety, 2008. Struktur dan Pola Hubungan Sosial Ekonomi Juragan Dengan Buruh di Kalangan Nelayan Pantai Utara Jawa Barat, Jurnal Kependudukan Padjajaran, Vol. 10 No 1.

Trio, Joni Wibowo, dkk, 2016. Dinamika Sosial Nelayan Dalam Arena Ekonomi, Jurnal Sosiologi Reflektif , Volume 11. No 1.

Wasak, Martha, 2012. Keadaan Sosial Ekonomi Masyarakat Nelayan di Desa Kinabuhutan Kecamatan Likupang Barat. Kabupaten Minahasa Utara, Sulawesi Utara, Jurnal Pacific, Vol. 1 No 7.
Wayan, I Tagel Eddy, Anak Agung Ayu Rai Wahyuni. 2019. Revolusi Biru dan Human SecurityNelayan di Kusamba Klungkung, Jurnal Ilmuilmu Budaya, Vol XIX No 1. 